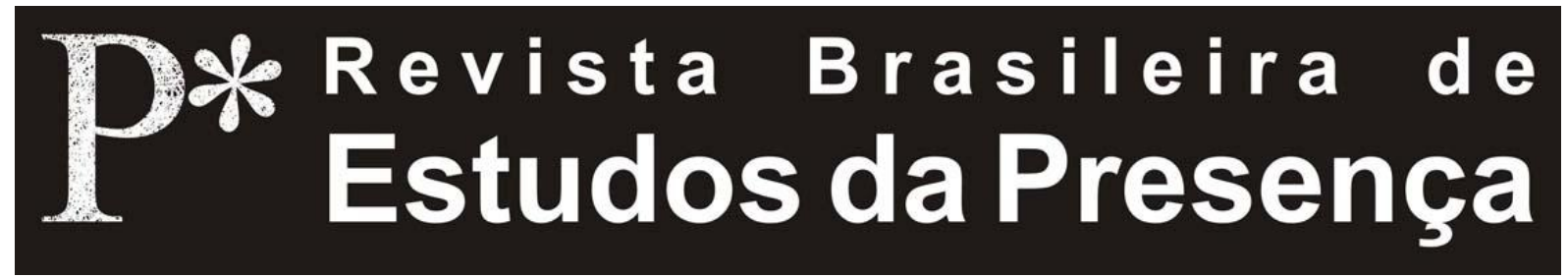

\title{
Longe dos Olhos, Perto do Coração
}

\author{
Edelcio Mostaço \\ Universidade do Estado de Santa Catarina - UDESC
}

\begin{abstract}
RESUMO - Longe dos Olhos, Perto do Coração - O artigo especula sobre diferenças entre culturas de presença e culturas de sentido, apontando as primeiras como atadas a certas configurações cósmicas e as segundas caracterizadas pela cisão do eu que engendra a separação do mundo. Destaca o papel do cristianismo como preparação mental para o advento do regime de ficção nas culturas ocidentais, ao enfatizar a presença através da ausência.
\end{abstract}

Palavras-chave: Presença. Representação. Signo.

ABSTRACT - Far from Eyes, Close to Heart - The article speculates about differences between presence cultures and sense cultures, indicating the former as attached to certain cosmological frames and the latter characterized by the division of the self which engenders the separation of the world. It highlights the role of Christianity as a mental preparation for the advent of the fiction regime on western cultures, emphasizing the presence through the absence.

Keywords: Presence. Representation. Sign.

RÉSUMÉ - Loin des Yeux, Auprès du Couer - L'article spécule sur les différences entre les cultures de la présence et les cultures de sens, pointant les premiers comme attachés a certain cosmologies et les seconds caracterérisé par le clivage du moi qui donne lieu à la separation du monde. Souligne le rôle du christianisme comme la préparation mentale pour l'avènement du régime de fiction dans les cultures occidentales, qui reinforce la présence par l'absence.

Mots-clés: Présence. Representation. Signe.

Edelcio Mostaço, Longe dos Olhos, Perto do Coração.

R.bras.est.pres., Porto Alegre, v.1, n.2, p. 301-311, jul./dez., 2011.

Disponível em http://www.seer.ufrgs.br/presenca 
Um mar imenso separa um soldado de sua casa, afastado há vários anos desde que a guerra se iniciou. Sua solidão e angústia o levam a pegar um pouco de barro e com ele confeccionar uma pequena estatueta de mulher, posteriormente depositada junto às outras em coleção, a quem ele acaricia, conversa e reitera seu amor, procurando desse modo aplacar uma ausência, ilusoriamente convicto de que o barro é carne humana, capaz de ouvi-lo e também o sentir.

Esse soldado se chama Menelau, a mulher Helena, e a cena faz parte da Ilíada, um dos marcos fundadores da arte ocidental. Numa cena atual, o soldado estaria no Iraque, a namorada no Texas e eles utilizariam algum messenger para estabelecer contato. Mas tanto na vastidão da Grécia Arcaica quanto nos confins do Império contemporâneo, as distâncias são reais, as carências e faltas efetivas e todos sabem que empregam paliativos para tentar sanar uma realidade irreversível: a ausência do outro.

Ausência que se quer preenchida pela presença, falta que se quer suprimir através da aproximação. Parece ser essa a conjugação mais elementar da fissura que acompanha os humanos desde os primórdios, fendendo em partes aquilo que deveria estar unido. Ausência e presença constituem as duas instâncias que nos acompanham pela história, estão na base de todos os retornos - mesmo os eternos -, expondo como chaga uma ferida que não fecha, forçada ou deliberadamente, gritando sua dor. Vamos reencontrar sempre essas instâncias em todas as formas de representação, esses expedientes vicários encontrados ao longo dos tempos para substituir o irremediável, para suprir o impossível, ilusoriamente conduzidos por uma ânsia que se deseja aplacar.

Estar presente é estar aqui, colado a mim, no limite do toque de minha mão, à vista dos olhos e, supremo deleite, para meu gozo. Nas ausências, a memória, as recordações, as substituições tentam suprir as faltas e, muito provavelmente, foram essas operações do espírito desenvolvidas exatamente para isso: condenados que estamos às perdas e separações, às contínuas ausências

Edelcio Mostaço, Longe dos Olhos, Perto do Coração.

R.bras.est.pres., Porto Alegre, v.1, n.2, p. 301-311, jul./dez., 2011.

Disponível em http://www.seer.ufrgs.br/presenca 
trazidas pela morte, inventamos expedientes que almejam, apesar da precariedade, tornar presente o que foi perdido.

Tais mecanismos são de especial relevância para o teatro. Nas origens, a cena foi um modo de tornar presente o que havia se tornado ausente, ou ocorrido num tempo mítico e separado, não acessível senão por intermédio da presentificação de que a cena é capaz. A saga de Dioniso era anualmente dada à vista nos cultos de mistério que o honravam, mas exclusivamente para uma plateia de devotos e iniciados; deuses e heróis trágicos povoavam a cena nos concursos da polis, configurando uma galeria mítica de figuras já distantes que, agora reinvestidas pelos sortilégios da representação, tornavamse atuais e podiam ser, ainda que vicariamente, tornadas presentes.

Memória, recordações e substituições constituem instâncias fundamentais para uma pessoa cindida, funcionando, para o equilíbrio do ser humano, como parcela indispensável de seu ser-no-mundo ${ }^{1}$. Na atual fase da pós-modernidade, contudo, um complexo baralhamento de instâncias turva essa apreensão em seus verdadeiros contornos. Se claro está o caráter representacional e substitutivo inerente à estatueta de Menelau, não se pode dizer o mesmo quanto à namorada via webcam, uma vez que ela está ali, efetivamente, chorando e mandando beijos; ainda que do outro lado do mundo, em fuso horário diverso, usando roupas de outra estação e suas lágrimas, ao escorrerem na tela do monitor do soldado, tenham de fato rolado pelo menos dois minutos antes, retidas pelo trânsito da nuvem. Mas, tanto a estatueta em sua matéria bruta quanto o messenger em seu aparente realismo são, literalmente, presenças equívocas, tão somente virtuais. Uma é barro, a outra um conglomerado de pontos luminosos dispostos na tela. Mas correspondem, no tempo e no espaço, aos meios disponíveis, naquela e nesta época, para aplacar a separação, possibilitar o contato e restituir o afeto permanentemente cobrado pela pulsão libidinal.

Nesse complexo jogo de possíveis, nessa contenda entre real e imaginário, as questões abertas em torno da 
presença nas representações evocam situações extremamente amplas, que abrangem desde as dicotomias platônicas em torno da Verdade e da Aparência e se estendem até as atuais interrogações implicadas no código genético: o que o filho guardará ou não de semelhança com o pai? Tal complexidade pode ser explorada numa variedade de tipologias, envolvendo não apenas os sistemas de conhecimento - a filosofia, a biologia, a antropologia, a semiótica, a psicanálise, entre outras - como, mais incisivamente, as distintas disposições comportamentais de diferentes culturas frente a tais fenômenos, adensando a quantidade de respostas frente a situações assemelhadas. Para ser mais direto: como reagir e que atitude tomar em relação à representação da presença (e, igualmente, a ausência, uma vez que essa é sua irreversível contrapartida)? Interpretála ou senti-la?

A primeira operação caracteriza as culturas fundeadas no signo, que enxergam o mundo como uma exterioridade absoluta em relação à consciência e, por isso, instituem uma separação entre a coisa e o eu. Mas quando o signo não dá conta de atribuir sentido ao ato ou ao sentimento que o acompanha, prefere calar-se. À segunda, ao contrário, não importa tanto o significado do fenômeno, mas sua intensidade - a dor, o amor, a culpa, o remorso, a solidariedade, não importa o afeto mobilizado - que a presença ou a ausência infundem. Existenciais e carnais, tais culturas exprimem, sem mediações muito complexas, os avatares do corpo, sobrepondo-os a qualquer situação.

Tendo por base essas distintas configurações de respostas, é possível elaborar uma mais ampla tipologia de culturas, mais idealizada do que real, aqui aduzida tão somente para permitir exemplos e contrastes. Vejamos um pequeno quadro de suas características mais salientes para explorar as diferenças e semelhanças que estabelecem em relação à questão da presença.

a) A autorreferência maior numa cultura de sentido é o pensamento, expresso pela consciência, enquanto a mesma dimensão, numa cultura da presença, é ocupada pelo corpo.

Edelcio Mostaço, Longe dos Olhos, Perto do Coração.

R.bras.est.pres., Porto Alegre, v.1, n.2, p. 301-311, jul./dez., 2011.

Disponível em http://www.seer.ufrgs.br/presenca 
b) Se há privilégio do pensamento na primeira, ela divide o homem e o mundo como duas instâncias irredutíveis uma à outra, cabendo-lhe um papel ontológico central e ao mundo, singularmente tomado como coisa, um papel acessório. Assim, subjetividade e sujeito tornam-se as instâncias centrais administrando esse universo de sentidos, fazendo o $\mathrm{eu}$ cintilar a todo instante. Na cultura de presença, ao revés, os corpos fazem parte de uma cosmologia (foram criados por uma divindade) e não são percebidos como excêntricos ao mundo, mas nele se percebem integrados. Na primeira, as coisas detêm uma coisidade que lhes é imanente e percebida como brutal, selvagem ou natural. Na segunda, as coisas, os seres do mundo, dependem de contextualização, e suas existências se confundem ou partilham a existência humana. O que explica porque os indianos reverenciam bovinos, enquanto os ocidentais os caçam em espetáculos de rodeio.

c) O conhecimento só é considerado legítimo se for produzido por um ato de pensamento inscrito numa dada ordem hermenêutica, avalia o primeiro modelo cultural. Enquanto é a revelação - em suas modalidades epifânica ou de desvelamento - a fonte confiável do saber nas culturas de presença, tomando os signos e sinais ao pé da letra, o que as torna abertas àquilo considerado irracional pelas culturas do primeiro grupo.

d) A partir dessa diferenciação, abrem-se as distinções em relação à avaliação dos signos. Para a cultura de sentido, o signo segue a clássica distinção de Saussure: o significante é sua parte material e o significado a parte espiritual; o que torna a primeira quase sempre desprezível ou relutantemente tolerada em benefício da segunda, esta sim a dourada emanação do saber, pois decorre do pensamento e da interpretação. Isso abre caminho para as grandes abstrações e substantivações daquilo que é tão somente matéria ou, no melhor dos casos, conjuntos de materiais ajuntados para conformar abstrações (o mercado, a arte, a saúde, a lavoura, o urbanismo etc.), assim banhadas por alguma categorização que lhes injete transcendência, velando suas naturezas enquanto coisas. Numa cultura de 
presença, contudo, os signos vêm carregados de emanações cósmicas, e suas diferenciações são unicamente instrumentais e ocasionais. O I Ching conforma hexagramas num número finito, à medida que é consultado, em função das forças celestes em trânsito naquele momento. $\mathrm{O}$ signo, assim, já estava inteiro concebido antes, cabendo ao demandante apenas circunscrevê-lo às suas circunstâncias de momento quando das invocações.

e) Através dessa última operação os seres humanos não apenas se adéquam a uma dada ordem, maior e eterna, como se comprazem em nela se sentirem integrados, o que lhes retira a angústia diante da ausência, exatamente pela continuada afirmação da presença. Romper tal ordem ou lhe perturbar o ritmo são operações a serem evitadas, mesmo quando não intencionais, o que habilita todas as transgressões como sérios desvios que exigem purgação ou penalização. Nas culturas de sentido, ao contrário, os indivíduos tendem a ver suas realizações como contínuas invenções e/ou inovações em relação ao já dado, havendo mesmo amplo incentivo às mudanças e transformações do mundo para melhor adaptá-lo às necessidades humanas. Este é o homem de ação. Cujos empreendimentos são tanto mais valorizados quanto acompanhados de um raciocínio que os embase, circunscrevendo o maior número possível de variáveis e, complementarmente, de efeitos a serem controlados em suas ações transformativas. Tal atitude está na base daquilo que é chamado planejamento e orienta toda a pesquisa científica. Em sociedades de presença os homens, quando necessitam alterar alguma coisa do mundo ou demandam por uma ação específica, costumam se valer da magia - ela que tem o poder de tornar presentes coisas ausentes ou ausentes coisas presentes. A magia nunca é apresentada ou tomada como uma invenção, sendo inscrita, antes, no rol dos conhecimentos herméticos, a poucos acessíveis e fruto de receitas secretas ou poderosas poções elaboradas num além. É o corpo, contudo, do xamã ou do demandante, o local preferencial para as práticas de magia. Fechar o corpo é 
defendê-lo dos perigos; dançar em círculos um modo de espantar maus agouros.

f) Se a ordem cósmica manifesta-se no plano humano nas culturas de presença, é o espaço a dimensão mais intensa e imediatamente nelas percebida e vivida, mais intensamente conotada. Nas culturas de sentido é o tempo que desfruta essa primazia, uma vez que uma equação paralógica ajunta tempo e consciência. A história, nessa acepção, é uma típica disciplina ligada ao tempo; assim como a filosofia, quando interroga o ser em suas infinitas ocorrências no tempo. Transformar $\mathrm{o}$ mundo é uma operação mais vivamente surpreendida no tempo que no espaço, sendo uma carreira de executivo, por exemplo, mais bem dimensionada através de seu tempo de experiência nesta ou naquela função, ou seja, sua presença aqui e ali.

g) Um diverso modo de operar faz bifurcar os dois tipos de cultura em relação à violência e à política. Nas culturas de presença são os corpos as fontes e escudos empregados nas lutas e nas disputas pelo mando. Em guerras e batalhas os confrontos homem a homem tendem a ganhar preponderância quanto à defesa ou ataque de espaços controlados. Nas culturas de sentido tal violência dos corpos é administrada, deslocando-a para um lugar vazio, mas significativo: o poder. Os sistemas políticos representativos efetuam uma síntese, mas igualmente uma escamoteação da violência original, sob a forma de um imponderável contrato social. Assim, quanto mais ela quer ser dirigida pelo sentido, mais legislativa se torna. O contraponto a esse poder são os corpos, daí as invasões, as marchas e passeatas, as greves, as ocupações que continuadamente desafiam a legislação e reintroduzem a presença violenta em culturas que desejariam vê-la bem longe, dissolvida na regra polida dos sufrágios e comitês de representantes. Na cidade de Platão eram os guardiões-filósofos os encarregados de dirigi-la e administrá-la; nos nossos tempos também não faltam vínculos entre poder e saber lembrando, ainda uma vez, que aquele que sabe deve ser o dirigente, porque conhece o sentido. 
h) Numa cultura de sentido, o evento está preponderantemente associado à inovação e seu valor de surpresa. O que explica feiras, congressos, festivais, encontros e quejandos como ocasiões de novidades, oportunidades e surpresas; bem ao contrário das culturas de presença, onde tais ocorrências reiteram uma renovação de hábitos e costumes ${ }^{2}$.

Essa última tipologia afeta sobremaneira as distinções quanto à arte e ao caráter por ela assumido nas duas tipologias de culturas aqui postas em destaque, notadamente naquilo que se refere à ficção. A ficção é uma decorrência do sentido, uma operação da consciência, pois estrutura-se inteiramente sobre a representação, sobre a reapresentação. Para que ocorra, torna indispensável articular uma função de jogo e reflexividade por parte daquele que a desfruta, sendo esta primeira condição a capacidade de desdobramento. É a razão pela qual sua fórmula clássica é o era uma vez (situando o tempo) e o num reino distante (situando o espaço), ambos em sua acepção de invocação de algo ausente. Ou seja, a ficção mobiliza forte capacidade de trânsito entre aquelas condições fingidas, inventadas, ou que já não mais existem, e as contemporâneas, os pretéritos, os presentes e, em vários casos, os futuros, para tanto apelando para a capacidade de jogo. Reinvestindo, portanto, a condição de presença através de uma condição inteiramente virtual, liminar.

Esse mesmo procedimento está na base da mais difundida e arraigada crença da civilização ocidental: o cristianismo. Sua teologia trabalha diversas vezes sobre o princípio do velar e do desvelar, do estar e do desaparecer. Cristo desfruta de uma dupla natureza, é deus e também é homem. Sua origem divina foi previamente anunciada em vários rincões, mas apenas uns três reis magos deram crédito à notícia. Após a adolescência desapareceu, para reaparecer a seguir, agora imbuído de poderes que antes nunca tinha manifestado. Após sua morte é enterrado, mas desaparece do túmulo três dias após, deixando seus poucos seguidores perplexos com sua ausência, mas infinitamente mais convictos de sua santidade. Quadros e esculturas medievais fixaram 
esse instante, perpassado de virtualidade, no momento em que os olhares se dirigem para um caixão vazio ${ }^{3}$.

Esses diversos aparecimentos e desaparecimentos fazem parte de sua epifania. Exigiram dos cristãos primitivos, contudo, o alargamento de suas percepções, contribuindo enormemente para estabilizar entre as populações o jogo necessário à ficção. Até que fosse instituído, já ao final da Baixa Idade Média, o ritual da missa, onde uma nova invocação desse jogo especular entre ausência e presença vai ganhar seus definitivos contornos: a comunhão. Nela, come-se o corpo da divindade e bebe-se seu sangue, tornando-o outra vez presente. Deixemos de lado a matriz antropofágica sustentando tal passagem (o que nos reenviaria para as questões antes referidas em relação ao controle da violência), para ficarmos tão somente em seus aspectos eucarísticos. Considerado o ápice ritual de culto ao mito, representa o instante em que a divindade, de natureza celestial e presente num além, novamente se corporifica no plano terrestre, distribuído a todos e a cada um sob o formato de pão e vinho.

São contínuos, portanto, os apelos ao velar e ao desvelar, ao surgir e ao desaparecer, ao estar e ao não estar - ou seja, à sua condição de presente/ausente, dando destaque ao fenômeno da reapresentação de um corpo/espírito. Estamos diante de uma teologia, portanto, que ensejou e difundiu largamente o jogo mental que sustenta a ficção. Ficção que, em seus modelos clássicos, nasceu nos primórdios do século XVII, época que, não fortuitamente, assiste também ao nascimento das bases culturais que engendraram as modernas sociedades europeias, fortemente sustentadas na instância do sentido ${ }^{4}$.

Os grandes arquétipos de narradores invocados por Walter Benjamin são o camponês sedentário e $o$ marinheiro viajante, dois tipos que acumulam episódios e, especialmente, sentem prazer em contar suas aventuras bem como acrescentar, revirar, dispor, subtrair ou multiplicar seus ingredientes - dando asas à imaginação, os feitos próprios ou de outros. É através do expediente inventivo, portanto, que sustentam suas narrações; ou 
seja, desafiam o sentido, o invertem ou modulam, acrescentando sombra onde havia certeza, dúvida onde havia crença, probabilidade onde havia ordem, reintroduzindo - ainda que vicária - a presença onde, efetivamente, só existe ausência.

A conclusão é paradoxal? Sem dúvida. O paradoxo, assim como outras operações de raciocínio e de linguagem que lhe são conexas, apenas é possível quando existe lógica, esta aguda censora do universo do sentido.

\begin{abstract}
Notas
${ }^{1}$ Vejamos como Heiddeger examina essa questão: "A presença é um ente em que, sendo, está em jogo seu próprio ser. Na constituição de ser do compreender, o 'estar em jogo' evidenciou-se como o ser que se projeta para o poder-ser mais próprio. Esse poder-ser é o em virtude de, onde a presença é sempre como ela é. Em seu ser, a presença já sempre se conjugou com uma possibilidade de si mesma" (Heiddeger, 2008, p. 258).

${ }^{2}$ A tipologia aqui esboçada foi sugerida por Hans Ulrich Gumbrecht, mas segui apenas seus pontos centrais, modificando exemplos e argumentos. Ver Gumbrecht (2010).

${ }^{3}$ Ver, a esse respeito, a percuciente análise de Didi-Huberman (1998, p. 40).

4 “A partir do século XVII, todo o domínio do signo se distribui entre o certo e o provável: isso quer dizer que não seria mais possível haver signo desconhecido, marca muda. Mas, sim, que só há signo a partir do momento em que se acha conhecida a possibilidade de uma relação de substituição entre dois elementos já conhecidos. $\mathrm{O}$ signo não espera silenciosamente a vinda daquele que pode conhecê-lo: ele só se constitui por um ato de conhecimento. É aqui que o saber rompe seu velho parentesco com a divinatio", conforme sustenta Foucault (1992, p. 74).
\end{abstract}

\title{
Referências
}

DIDI-HUBERMAN, Georges. O que Vemos, o que nos Olha. Tradução de Paulo Naves. São Paulo: Editora 34, 1998.

FOUCAULT, Michel. As Palavras e as Coisas. Tradução de Salma Tannus Muchail. São Paulo: Martins Fontes, 1992.

GUMBRECHT, Hans Ulrich. Produção de Presença - o que o sentido não consegue traduzir. Tradução de Ana Isabel Soares. Rio de Janeiro: Editora Contraponto/PUC Rio, 2010.

HEIDDEGER, Martin. Ser e Tempo. Tradução de Márcia Sá Cavalcante Schuback. Rio de Janeiro: Ed. Vozes-São Francisco, 2008. 
Edelcio Mostaço é Doutor em Artes pela Universidade de São Paulo e Professor Associado no Programa de Pós-graduação em Teatro na Universidade do Estado de Santa Catarina. É bolsista de produtividade do CNPq.

E-mail: edmost@uol.com.br

Recebido em Outubro de 2011 Aprovado em Dezembro de 2011

Edelcio Mostaço, Longe dos Olhos, Perto do Coração.

R.bras.est.pres., Porto Alegre, v.1, n.2, p. 301-311, jul./dez., 2011.

Disponível em http://www.seer.ufrgs.br/presenca 